\title{
Use of the angioscope for aortic endovascular repair
}

\author{
William Y. Shi, Arminder S. Jassar \\ Corrigan Minehan Heart Center, Massachusetts General Hospital, Boston, MA, USA \\ Correspondence to: Arminder S. Jassar. Division of Cardiac Surgery, Massachusetts General Hospital, Assistant Professor of Surgery, Harvard Medical \\ School, 55 Fruit Street, Cox 630, Boston, MA 02114, USA. Email: ajassar@mgh.harvard.edu.
}

Submitted Jul 23, 2021. Accepted for publication Oct 05, 2021.

doi: 10.21037/acs-2021-taes-21

View this article at: https://dx.doi.org/10.21037/acs-2021-taes-21

\section{Introduction}

During aortic arch replacement, hypothermic circulatory arrest permits a bloodless surgical field that allows evaluation of the extent of disease and planning for the ensuing repair. However, the descending thoracic aorta remains hard to visualize. There has been a recent increase: in the use of the frozen elephant trunk (FET) technique, whereby an endovascular stent graft is deployed into the descending aorta during aortic arch surgery, performed under direct vision during the period of circulatory arrest (1). Inadvertent malposition of a device (e.g., into the false lumen of the descending thoracic aorta during arch repair for acute Debakey I dissection) can have catastrophic consequences. A flexible scope permits inspection of the distal thoracic aorta for more accurate placement of devices. We herein describe an illustrative case and our approach to angioscopy in aortic arch surgery.

\section{Clinical vignette}

The case is a 57 -year-old female, presenting with a $6.2 \mathrm{~cm}$ distal aortic arch aneurysm with a $4.0 \mathrm{~cm}$ ascending aorta. There was no suitable proximal landing zone for an endovascular stent graft, even if a left subclavian-carotid bypass was undertaken. A left thoracotomy approach was undesirable given her poor respiratory function, therefore, she was brought to the operating room for aortic arch replacement with FET placement via median sternotomy.

\section{Surgical technique}

\section{Preparation}

The patient was placed supine on the operating table, bilateral radial and femoral arterial blood pressure monitoring lines were inserted, as was a temperaturesensing Foley catheter. Cerebral oximetry monitoring was attached and a Swan-Ganz catheter placed.

\section{Operation}

The right axillary artery was used for arterial inflow for cardiopulmonary bypass and for providing antegrade cerebral perfusion during corporeal circulatory arrest. Additionally, we performed direct ostial cannulation of the left carotid artery using a balloon catheter to provide bilateral antegrade cerebral perfusion. We cooled to $20^{\circ} \mathrm{C}$ given the uncertain duration of circulatory arrest. If the expected duration of circulatory arrest is short, we often cool to moderate hypothermia at $24-28^{\circ} \mathrm{C}$.

For angioscopy and visualization of the distal aortic lumen, we used a flexible, sterilizable bronchoscope (Olympus BF Q180-AC) with an outer diameter of $5.5 \mathrm{~mm}$ and length $60 \mathrm{~cm}$. The bronchoscope is kept sterile and routinely used for all elective hybrid aortic cases, remaining readily available for emergency acute aortic dissections.

Once at 20 degrees, circulatory arrest was commenced and the aortic arch was resected to zone 2. A flexible suction catheter was inserted into the descending aorta to ensure a 
bloodless field. The sterile bronchoscope was advanced into the distal arch and descending aorta to examine the distal landing zone for FET deployment. The distance from the scope's tip to the aortic rim was used to help determine the distance to the FET landing zone.

A pigtail catheter preloaded with a Lunderquist guidewire (Cook Medical, Bloomington, Indiana) was advanced to the distal descending aorta under aortoscopic vision. The pigtail catheter was removed, and the FET stent graft advanced over the Lunderquist wire. The aortoscope was used to confirm a co-linear position of the stent graft, as well as ensuring an adequate landing zone in the normal portion of the aorta distally. The stent graft was then deployed. The aortoscope is used to confirm the stent graft is flush with the wall of the aorta. In non-dissection cases, gentle balloon dilation can be performed under vision, if deemed necessary. The aortic arch anastomosis was performed at the level of the stent graft's proximal edge, taking care to incorporate it into the anastomosis. An external strip of felt can be used for reinforcement, if required. After this anastomosis, distal perfusion was resumed via the side-arm of the graft. The left subclavian, carotid, and innominate arteries were anastomosed to the respective limbs of the Siena ${ }^{\mathrm{TM}} \mathrm{graft}$ (Vascutek, Inchinnan, UK). A graft-to-graft anastomosis was performed to complete the neo-ascending aorta.

\section{Completion}

The cross clamp was removed, anastomotic sites inspected to determine the need for repair sutures, atrial and ventricular pacing wires were attached, and the patient weaned from cardiopulmonary bypass. Hemostasis was ensured and standard closure performed.

\section{Comments}

As the FET technique has gained popularity, specially designed hybrid grafts have been developed and several techniques have been described to position the stent graft in the distal aorta. The stent graft can be deployed with or without the use of a guidewire to direct stent placement, however, direct visualization of the distal landing zone of the stent graft is often difficult, or not possible. When a guidewire is used, it is usually placed retrograde via the femoral artery utilizing either fluoroscopy or intravascular ultrasound (IVUS), especially for patients with aortic dissection, when the wire must be positioned in the true lumen. This requires femoral arterial access (7-8
French when utilizing IVUS) and use of a hybrid room or portable fluoroscopy machines for wire visualization $(2,3)$. Aortoscopy is a useful tool to guide FET placement during aortic arch replacement, as it obviates the need for either blind placement of the stent graft or need for fluoroscopy and IVUS, which can be cumbersome during open surgery. It enables the surgeon to visualize the descending aorta, which would otherwise not be possible.

Assessment of distal aortic pathology enables more controlled positioning of the FET, especially when performing aortic arch replacement with a FET for aortic dissection. In such cases, the scope can be used to examine for intimal tears in the distal aortic arch and descending aorta. Here, should an intimal tear in the descending aorta be visualized, the scope is useful in ensuring that the guidewire remains in the true lumen throughout its course and that the FET covers the portion of the aorta with the intimal tear.

It is also useful when performing the FET procedure in cases of aneurysm, to avoid inadvertent insertion of the device into the aneurysm sac, and allow the distal landing zone to be evaluated. The scope permits shared visualization of the otherwise non-visualizable distal aorta and is thus a useful teaching tool for surgical residents and the entire operating room team.

\section{Acknowledgments}

Funding: None.

\section{Footnote}

Conflicts of Interest: The authors have no conflicts of interest to declare.

Open Access Statement: This is an Open Access article distributed in accordance with the Creative Commons Attribution-NonCommercial-NoDerivs 4.0 International License (CC BY-NC-ND 4.0), which permits the noncommercial replication and distribution of the article with the strict proviso that no changes or edits are made and the original work is properly cited (including links to both the formal publication through the relevant DOI and the license). See: https://creativecommons.org/licenses/by-nc-nd/4.0/.

\section{References}

1. Shrestha M, Bachet J, Bavaria J, et al. Current status and 
recommendations for use of the frozen elephant trunk technique: a position paper by the Vascular Domain of EACTS. Eur J Cardiothorac Surg 2015;47:759-69.

2. Axtell A, Eagleton M, Conrad M, et al. Total arch replacement and frozen elephant trunk for acute

Cite this article as: Shi WY, Jassar AS. Use of the angioscope for aortic endovascular repair. Ann Cardiothorac Surg 2021;10(6):801-803. doi: 10.21037/acs-2021-taes-21 complicated Type B Dissection. Ann Thorac Surg 2020;110:e213-6.

3. Roselli EE, Bakaeen FG, Johnston DR, et al. Role of the frozen elephant trunk procedure for chronic aortic dissection. Eur J Cardiothorac Surg 2017;51:i35-9. 